\title{
Wear Analysis of Additively Manufactured Slipper-Retainer in the Axial Piston Pump
}

\author{
Agnieszka Klimek ${ }^{1}$, Janusz Kluczyński ${ }^{1}$, Jakub Łuszczek ${ }^{1}$, Adam Bartnicki ${ }^{1}$, Krzysztof Grzelak ${ }^{1}$, Marcin Małek ${ }^{2}$ \\ 1 Military University of Technology, Faculty of Mechanical Engineering, Institute of Robots \& Machine De- \\ sign, 2 Gen. S. Kaliskiego St., 00-908 Warsaw 49, Poland; agnieszka.klimek@wat.edu.pl (A.K); \\ janusz.kluczynski@wat.edu.pl (J.K); jakub.luszczek@wat.edu.pl (J.Ł); adam.bartnicki@wat.edu.pl (A.B); \\ krzysztof.grzelak@wat.edu.pl (K.G) \\ 2 Military University of Technology, Faculty of Civil Engineering and Geodesy, Institute of Civil Engineering, \\ Gen. S. Kaliskiego 2, 00-908 Warsaw, Poland; marcin.malek@wat.edu.pl (M.M) \\ * Correspondence: janusz.kluczynski@wat.edu.pl (J.K)
}

\begin{abstract}
The paper contains the results of the 100-hour test campaign of the Additive Manufactured (AM) spare part (retainer - slipper) dedicated for an exact axial piston pump. The material of the retainer-slipper has been identified by using energy dispersive spectroscopy and replaced by other - with similar material properties as the original one. The obtained spare part had been subjected to only one postprocessing type (sandblasting) to analyze the influence of the rough part after the AM process. The whole test campaign has been divided into stages, where after each stage microscopic measurements have been made. During microscopical investigation roughness and geometrical measurements were conducted. The results revealed that it is possible to replace parts in hydraulic pumps with the use of AM. 100-hour test campaign caused about $500 \%$ increase in the surface roughness of the pump's original part which was cooperated with the AM spare retainerslipper, without any damages to the test system.
\end{abstract}

Keywords: Additive manufacturing, wear analysis, mechanical properties, H13 tool steel

\section{Introduction}

Additive manufacturing is recently in the interest of many research teams in the whole world. It is still especially focused on technological and process topics. In the last two years, there is also visible growth in the usage of AM in supply chains and spare parts analysis. This phenomenon was described by Frandsen et al. [1]. Clearly, then, earlier works were connected with some exact application or case studies analysis [2-5] but mostly those kinds of works had a form of preliminary analysis with highlighting of fundamental problems during application of parts obtained using additive manufacturing. Additionally, a lot of research works connected with the application were focused on functional prototypes [6-9] where final parts were obtained using conventional manufacturing methods. Present trends in professional AM systems development are mostly focused on the usage of that kind of technology in final products [10]. It is strictly connected with a huge amount of research works connected with AM process analysis and data about the influence of different factors on the mechanical properties of produced parts [11-18]. Verboeket et al. [19] indicated that the form of AM technologies development allowed for growth in its direct usage for final product production. In the mentioned work, the authors highlighted that AM enhanced the potential of a buy-to-fly spin-off mechanism where the ability to reach lightweight, geometrically complex, and heavyduty parts allow for a reduction of material usage, fuel consumption, footprints, and total costs. Additionally, in the same work [19] it has been described that usage of AM in the context of spare parts/repair solutions in supplied chain intervention using local AM machine and local raw materials supply in in-situ and on-demand mechanism allowed for 
reaching the lower cost of transportation, raw materials, and finished goods, improved responsiveness with improved product availability. Also, factors for other entities were highlighted:

- for customers: increased customer service (healthcare) level,

- for customs: role changes due to potential bypassing,

- for society: reduced theft, bribery,

- for suppliers: reduced need for transportation,

- $\quad$ for manufacturers and repair agents: extended product life cycle.

There is also visible growth of interests in AM usage from an environmental point of view [20-24], and life cycle analysis [25,26]. An analysis made by Hapuwatte et al. in their work [26] indicated, that using AM is the most sustainable in cases where complex geometrical components are necessary, but also highlighting that a quantity of production will be a deciding factor for considering AM as a production method.

Despite all the above-mentioned strengths of AM of final products, usage of this method in hydraulic solutions is still marginalized. There are only a few works connected with additively manufactured parts dedicated to hydraulic solutions [27-29]. The main reason for this phenomenon is wearing product generation [30]. Continuous development of usage AM, especially in produced parts properties in-situ shaping in own research [3133] and life cycle assessments of hydraulic parts described by Wang et al. [34] where authors indicated advantages of AM, especially from the production maintaining and environmental points of view.

Hydraulic drives are very popular at heavy-duty machines like construction and mining equipment, power plants, or the marine industry. The reasons why hydraulic drives are so popular are: enormous power (when compared with mechanical or electric drives), easy control of the system, reliability and flexibility.

Reliability is one of the most important factors during operating working equipment. Proper planning of the equipment work and its diagnostic are key for the successful cooperation of resources, labor costs, and accomplishing tasks within a deadline. The diagnostic systems installed on the machine, careful observation, and analysis of the operating parameters of the machine systems allow for the identification of flaws of elements before it is seriously damaged.

Unfortunately, even early detection of defects excludes the machine from use until a new part is ordered and replaced. Usually, the time of delivery of parts to the recipient is about six weeks, and currently, due to the interruption or problems with logistics chains, caused by the COVID-19 pandemic, this time may be extended. The situation when a machine is out of service results in significant delays and significant penalties. The only solution to this problem seems to be the short-term rental of the machine, which also generates costs - for a backhoe loader with a weight of about 10 tons and engine power of 70 $\mathrm{kW}$, the weekly costs are about USD 1000.

According to the literature [37], approximately $20 \%$ of all damages in hydraulic systems are pump damages, which are the key elements of the system. Due to the importance of this element, more effective methods of diagnosing them are in the interests of many researchers in the world [38-40]. One of the most popular types of hydraulic pumps is a variable displacement axial piston pump. Pumps of this type are characterized by high output power, high operating pressure, and compact design. The most common axial pump failures are damages to the feet of the slippers and the pistons, the slipper retainer, and the valve plate $[41,42]$. The damaged parts are shown in Figure 1. 

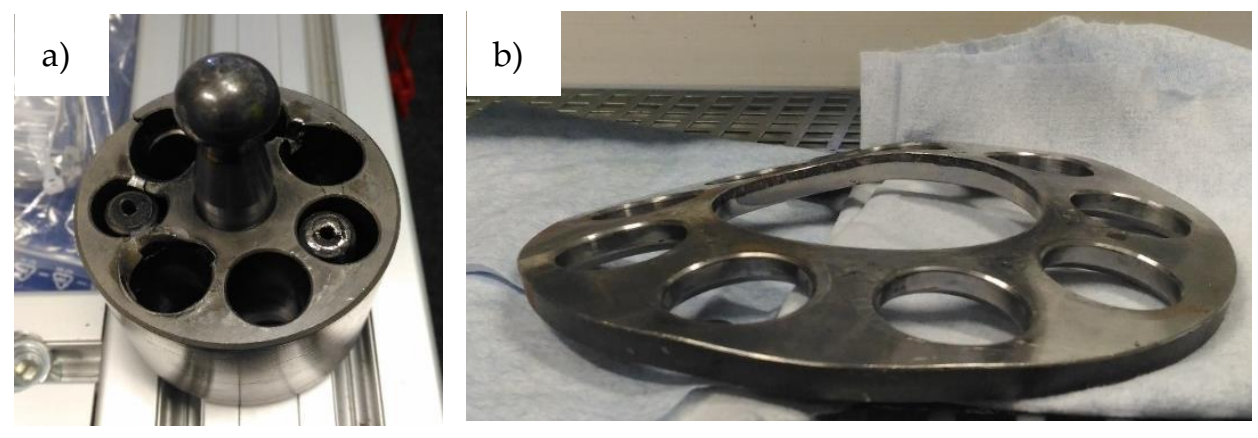

Figure 1. The damaged parts of an axial piston pump: a) cylinder block with pistons, b) slipperretainer

Those factors encourage authors of this work to analyze slipper-retainer in axial piston pump, especially from a wear resistance point of view to check the possibility of maintaining the operation of that kind of part in the case of damage and lack of available spare parts.

\section{Materials and Methods}

\subsection{Material}

Those factors encourage authors of this work to analyze slipper-retainer in axial piston pump, especially from a wear resistance point of view to check the possibility of maintaining the operation of that kind of part in the case of damage and lack of available spare parts.

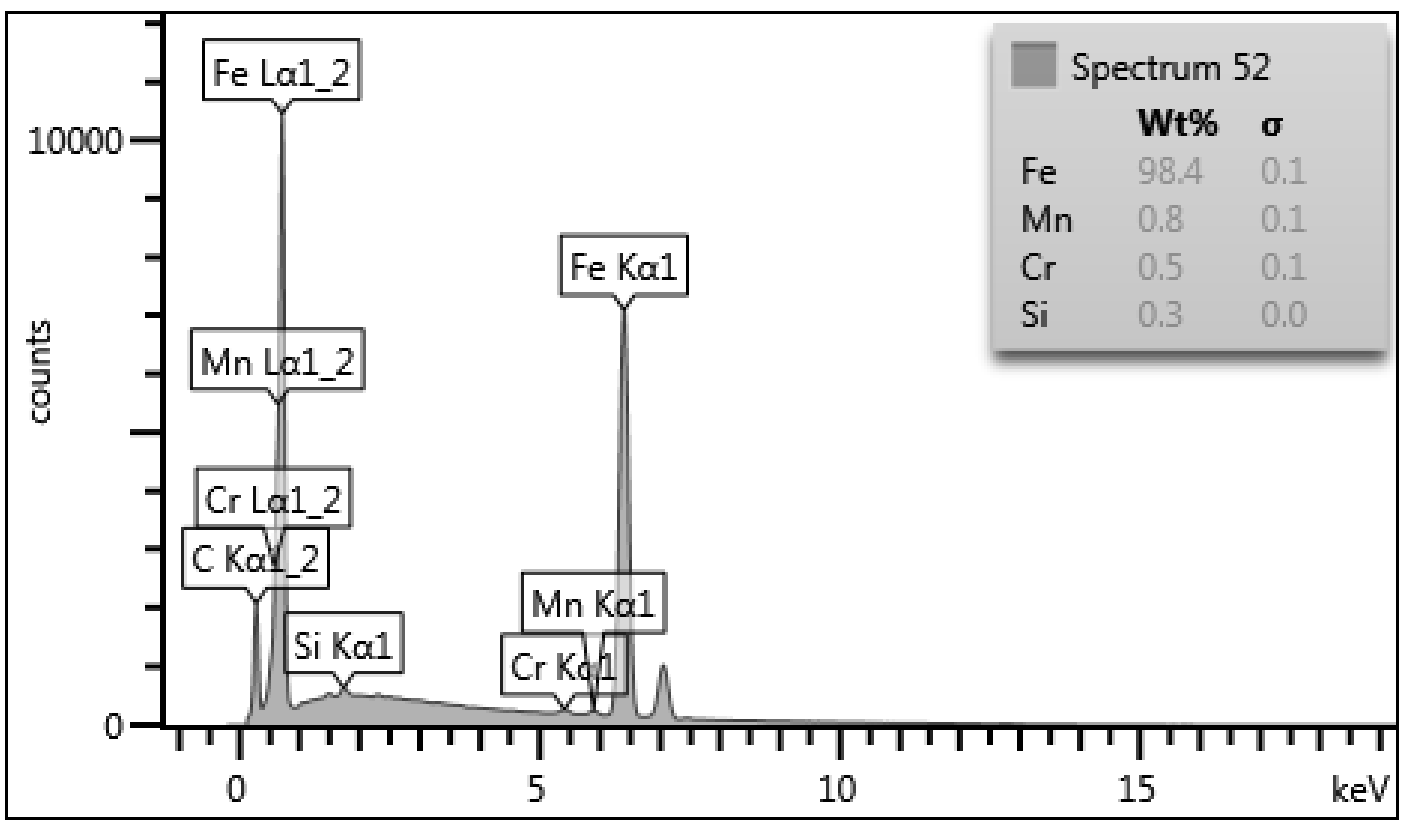

Figure 2. Chemical composition of analyzed slipper-retainer

Additionally, to improve the accuracy of material type detection, Rockwell hardness distribution measurements using a W-1460 hardness tester (KABID-PRESS, Warsaw, Poland) were conducted. Results are shown in Table 1. 
Table 1. Hardness measurements of the slipper-retainer

\begin{tabular}{|c|c|c|c|c|c|c|}
\hline $\begin{array}{c}\text { Measurement } \\
1\end{array}$ & $\begin{array}{c}\text { Measurement } \\
2\end{array}$ & $\begin{array}{c}\text { Measurement } \\
3\end{array}$ & $\begin{array}{c}\text { Measurement } \\
4\end{array}$ & $\begin{array}{c}\text { Measurement } \\
5\end{array}$ & $\begin{array}{c}\text { Average } \\
\text { Standard devi- } \\
\text { ation }\end{array}$ \\
\hline $38 \mathrm{HRC}$ & $41 \mathrm{HRC}$ & $43 \mathrm{HRC}$ & $44 \mathrm{HRC}$ & $40 \mathrm{HRC}$ & $41 \mathrm{HRC}$ & $2 \mathrm{HRC}$ \\
\hline
\end{tabular}

Based on the chemical composition analysis and hardness measurements of the slipper-retainer, the material was specified as AISI A3145 steel. That type of material is mostly dedicated to manufacturing parts of engines and motor vehicles that need high impact resistance, good tensile strength, and ductility. However, this steel in powder form is not offered by the suppliers on the market. To reach proper values of material properties H13 tool steel has been selected as substitute material, mostly because of its hardness at a level of $38 \mathrm{HRC}$ without any additional heat treatment directly after selective laser melting (SLM), which is a Powder Bed Fusion (PBF) AM processing (in accordance with ISO/ASTM 52900).

The metallic powder (CARPENTER TECHNOLOGY CORPORATION, Philadelphia, PA, USA) used for slipper-retainer replacement additive manufacturing was gas atomized H13 tool steel in the argon atmosphere. Obtained results using SEM, shown in Figure 3 revealed that powder particles had spherical shapes in a diameter of $15-45 \mu \mathrm{m}$.

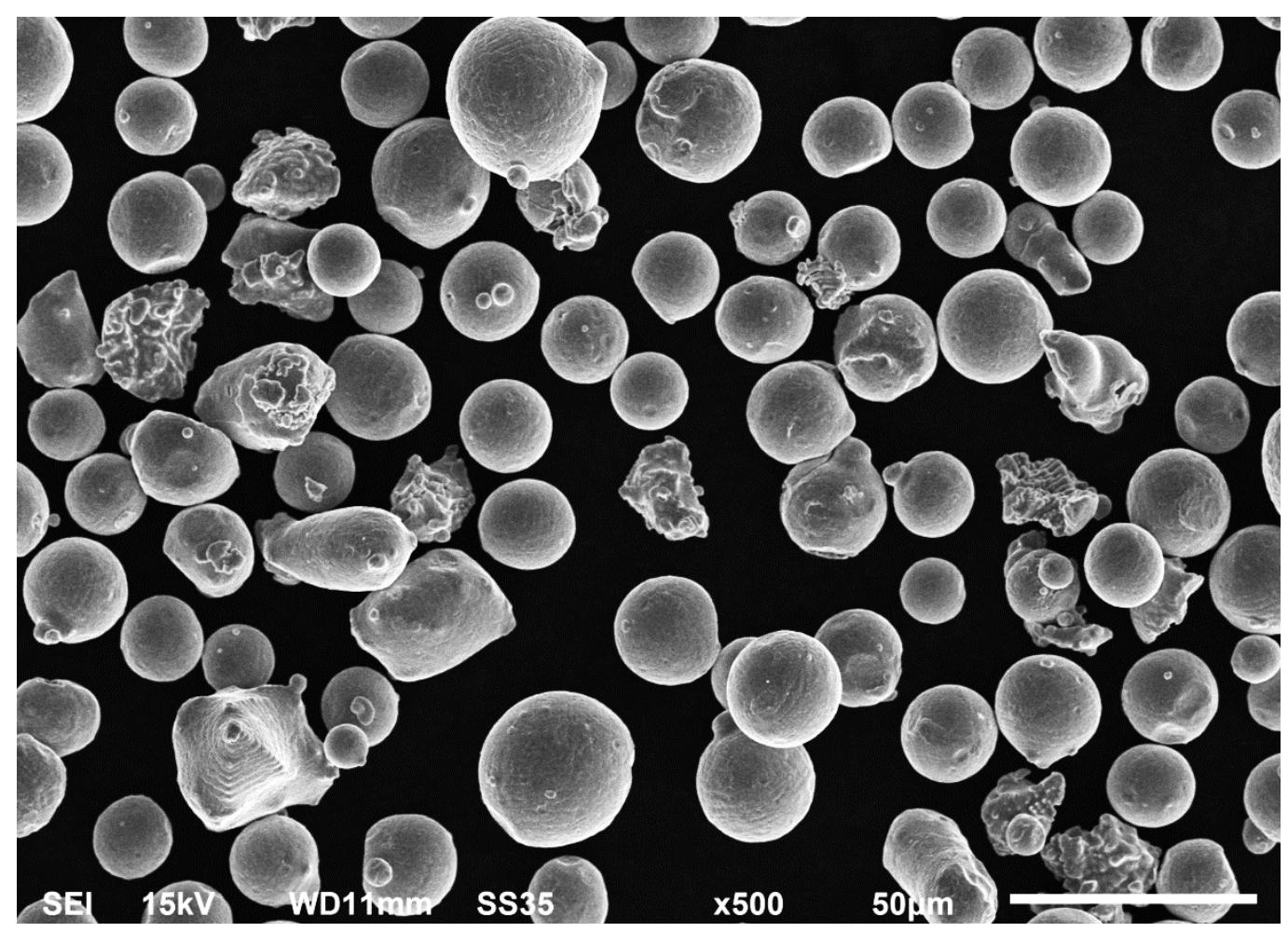

Figure 3. SEM image of H13L powder particles

The material chemical composition of the material is shown in table 2.

Table 2. H13 tool steel chemical composition

\begin{tabular}{|c|c|c|c|c|c|c|c|c|c|c|}
\hline $\mathrm{C}$ & $\mathrm{N}$ & $\mathrm{S}$ & $\mathrm{P}$ & $\mathrm{V}$ & $\mathrm{Mo}$ & $\mathrm{Cr}$ & $\mathrm{Si}$ & $\mathrm{Mn}$ & $\mathrm{Cu}$ & $\mathrm{Ni}$ \\
\hline \multicolumn{10}{|c|}{ weight [\%] } \\
\hline 0.35 & 0.06 & 0.01 & 0.01 & 1.02 & 1.27 & 5.38 & 1.13 & 0.38 & 0.02 & 0.10 \\
\hline
\end{tabular}




\subsection{Manufacturing process description}

The slipper-retainer for the test pump has been designed using reverse engineering based on simple caliper measurements covered by microscopical measurement verification. The test part (shown in figure 4) was designed using a CAD software (SolidWorks version 2021) and manufactured by means of the SLM 125HL machine (SLM Solutions AG, Lubeck, Germany).
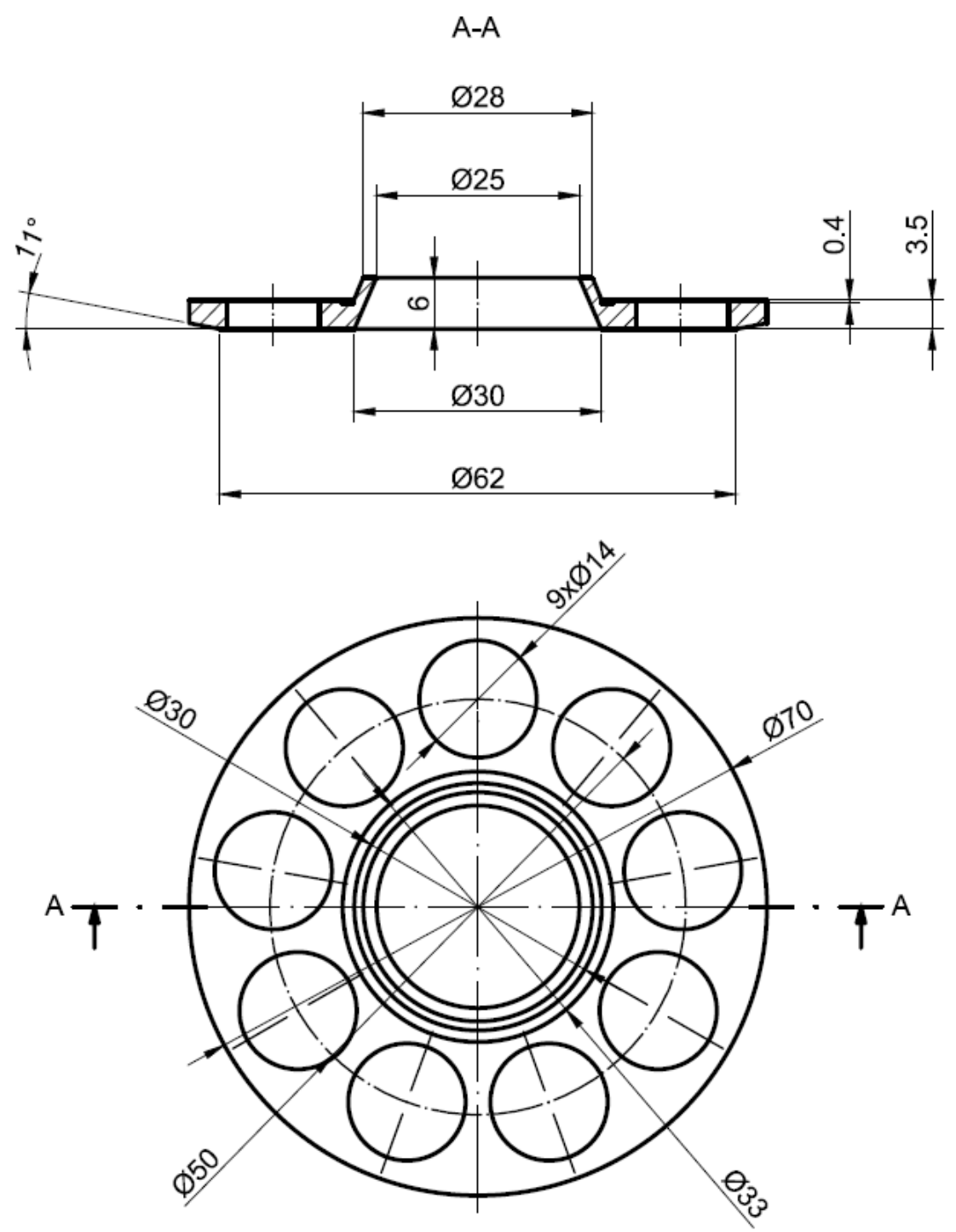

Figure 4. The slipper-retainer drawing with dimensioning

For the test part manufacturing, the default group of process parameters has been selected and specified in table 3.

Table 3. Parameters used for samples manufacturing

\begin{tabular}{|c|c|c|c|c|}
\hline $\begin{array}{c}\text { Layer thickness } \mathrm{l}_{\mathrm{t}} \\
(\mathrm{mm})\end{array}$ & $\begin{array}{c}\text { Laser power } \\
\mathrm{LP}(\mathrm{W})\end{array}$ & $\begin{array}{c}\text { Exposure velocity } \\
\mathrm{e}_{\mathrm{v}}(\mathrm{mm} / \mathrm{s})\end{array}$ & $\begin{array}{c}\text { Hatching distance } \\
\mathrm{h}_{\mathrm{d}}(\mathrm{mm})\end{array}$ & $\begin{array}{c}\text { Energy density } \\
\mathrm{Q}_{\mathrm{E}}\left(\mathrm{J} / \mathrm{mm}^{3}\right)\end{array}$ \\
\hline 0.30 & 168 & 710 & 0.12 & 58.64 \\
\hline
\end{tabular}


To avoid part deformations and warping during the process (caused by a high-temperature gradient), the test part has been manufactured with a solid base (it was shown in figure 5), which was cut out after the successful finish of the process using an electrodischarge machine (EDM). Support structures were generated only below the angled surface of the downskin.

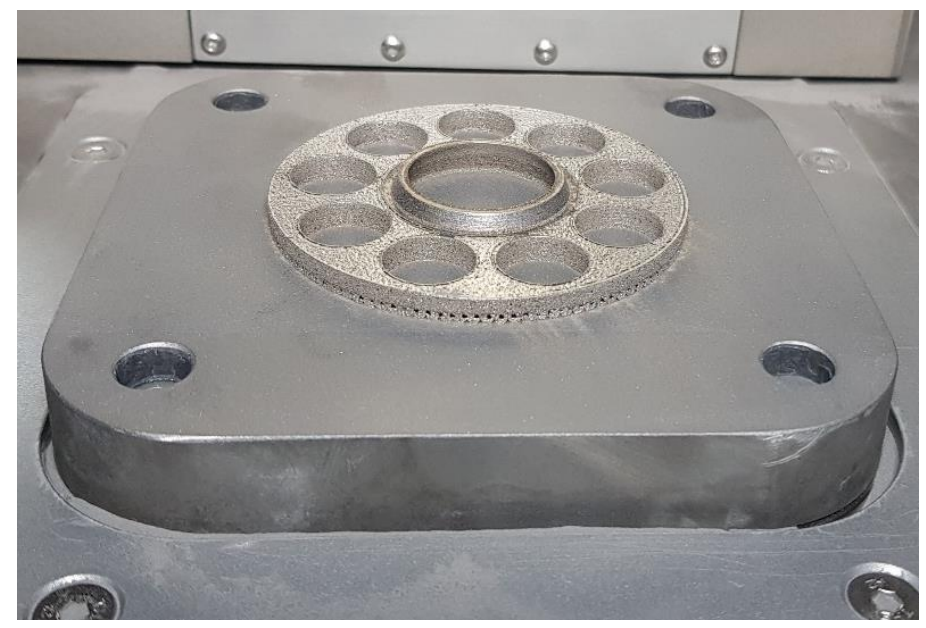

Figure 5. The slipper-retainer test part on the device's building platform

\section{Experimental}

\subsection{Methodology}

During the test, two main aspects were observed. The first one was the preservation of pump operating parameters. The second was pump elements wear analysis. The tested pump is a Hydraut PQ15 HLA2RS40X unit. The main operating parameters of this pump are shown in Table 4.

Table 4. Hydraut PQ15 pump main parameters

\begin{tabular}{|c|c|c|}
\hline $\begin{array}{c}\text { Max. operating pressure } \\
\text { (bar) }\end{array}$ & $\begin{array}{c}\text { Max. displacement } \\
\text { (cc/rev) }\end{array}$ & Max. speed (rpm) \\
\hline 250 & 15 & 1800 \\
\hline
\end{tabular}

In the field of hydraulic pumps, there is no clear procedure of durability tests, there are only "industry standards" provided by each company. Due to a lack of standards, an original test procedure was prepared. The total test time was set as 100 hours. This was based on the operating conditions presented in [43,44].

The test consists of 5 stages:

- 0 stage (preliminary test), the pump was operating without any load for one hour, the operating pressure was generated only by losses in the system.

- 1 st and 2nd stages, the pump was operating with a load of about 50, 75 bars for 8 hours respectively.

- 3rd stage, the pump was operating with a load of about 100 bars for 16 hours.

- 4th stage, the pump was operating with a load of 125 bars for 32 hours.

- 5th stage, the pump was operating with a load of 150 bars for 35 hours.

After each stage, the characteristic curves were measured. What is more, at chosen points the pump was re-assembled, the slipper retainer and pistons were carefully checked and the wear of the components was measured with an optical microscope. 


\subsection{Test station}

The test station was based upon an exiting one, presented in Figure $6^{\circ}$. The main parameters of hydraulic powerpack are tank capacity $65 \mathrm{dm}^{3}$, motor speed $900 \mathrm{rpm}$, and $3 \mathrm{~kW}$ of power. The hydraulic scheme of the test station is shown in Figure 6b. During the tests the oil temperature, flow and pressure were observed. The oil temperature range was $40-46^{\circ} \mathrm{C}$.
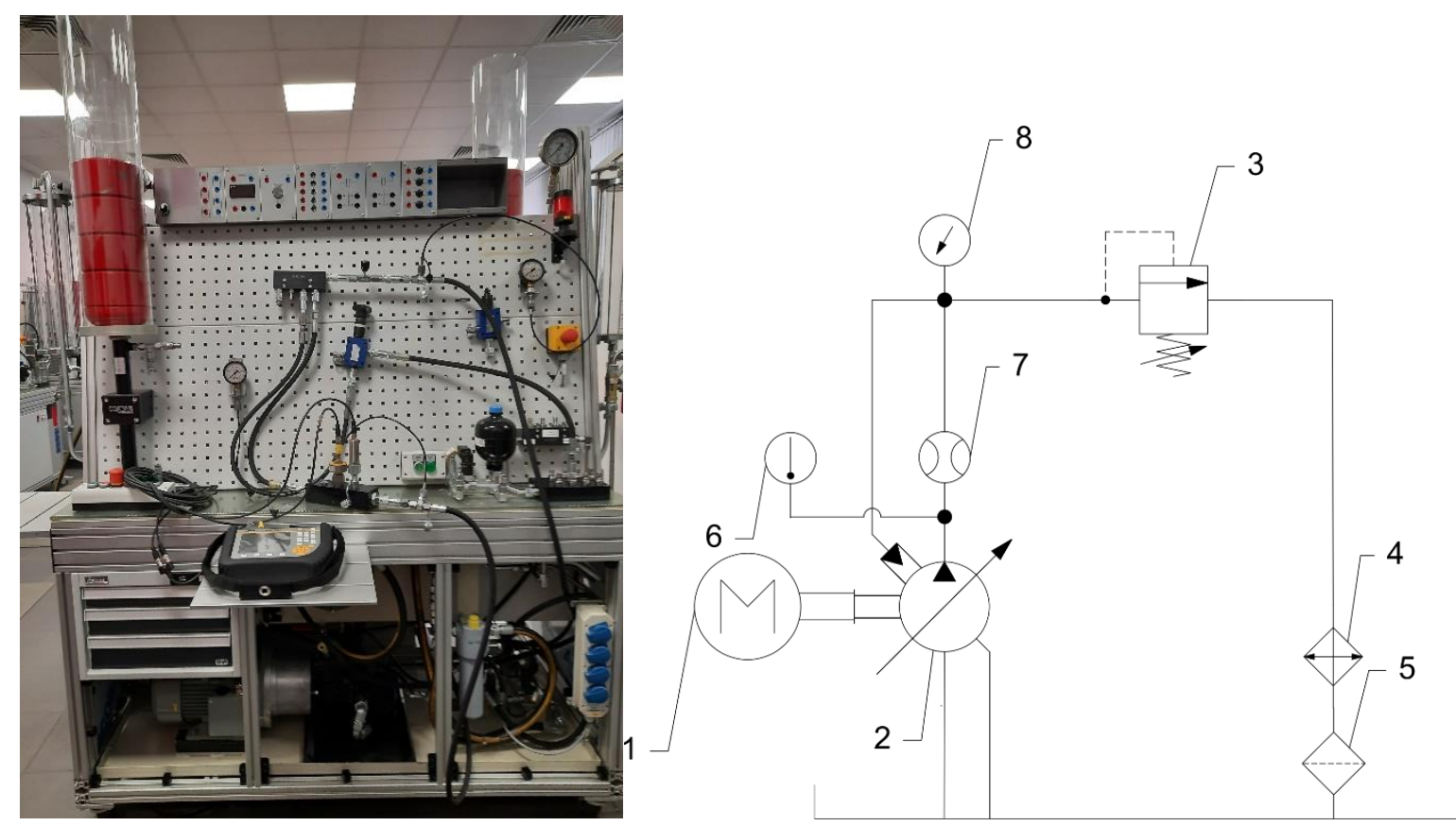

Figure 6. The test station: a) station b) hydraulic scheme: 1 - motor, 2 - tested pump, 3 - pressure relief valve (load valve), 4 - cooler, 5 - filter, 6 - temperature sensor, 7 - flowmeter, 8 - pressure sensor

\subsection{Microscopic investigation}

The microscopic measurement and wear investigation had been made by using a Keyence VHX 7000 optical microscope (Keyence International, Mechelen, Belgium). The ability to tilt the measurement lens in mentioned microscope allowed for wear analysis on the conical surface of the retainer-slipper part. During geometrical measurement of two pump pistons, 15 profile test lines have been made with a separation between lines equal to $0.3 \mathrm{~mm}$. The roughness measurement was carried out in accordance with PN ENISO 4287.

4. 


\section{Results and discussion}

The main three-part subjected to the highest wear were shown in figure 7 . Those surfaces are spherical retainer guide (1 in figure 7$)$, spherical surface in the slipper-retainer (2 in figure 7), and conical surfaces of two selected pistons ( 3 and 4 in figure 7 ). For each, analyzed part of the pump a detailed measurement has been made.

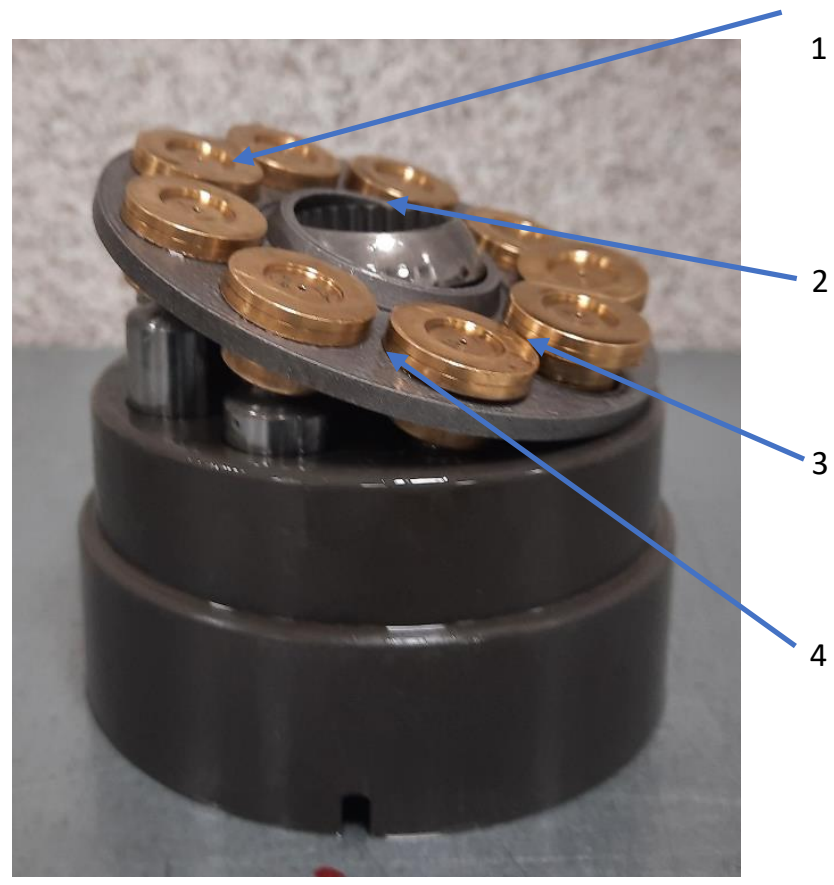

Figure 7. Four tested pump parts subjected to wear analysis: 1 - spherical retainer guide; 2 - spherical surface in the slipper-retainer; 3 - the conical surface of the 1st piston; 4 - the conical surface of the 2nd piston;

Wear measurements of the retainer guide related to Ra roughness are shown in table 5. For each level - five measurements were made. 
Table 5. Measured values of surface roughness in all tested pump parts

\begin{tabular}{|c|c|c|c|c|c|c|c|c|c|c|}
\hline $\begin{array}{c}\text { Test } \\
\text { no. }\end{array}$ & $\begin{array}{c}\text { Before } \\
\text { test } \\
(\mu \mathrm{m})\end{array}$ & $\begin{array}{c}\text { Time:1h, } \\
\text { load: } \\
0 \text { bar } \\
(\mu \mathrm{m})\end{array}$ & $\begin{array}{c}\text { Time:8h, } \\
\text { load: } \\
50 \text { bar } \\
(\mu \mathrm{m})\end{array}$ & $\begin{array}{c}\text { Time:8h, } \\
\text { load: } 75 \\
\text { bar } \\
(\mu \mathrm{m})\end{array}$ & $\begin{array}{c}\text { Time:16h, } \\
\text { load: } \\
100 \text { bar } \\
(\mu \mathrm{m})\end{array}$ & $\begin{array}{c}\text { Time:8h, } \\
\text { load: } \\
125 \text { bar } \\
(\mu \mathrm{m})\end{array}$ & $\begin{array}{c}\text { Time: } 8 \mathrm{~h}, \\
\text { load: } \\
125 \text { bar } \\
(\mu \mathrm{m})\end{array}$ & $\begin{array}{c}\text { Time: } \\
\text { 16h, } \\
\text { load: } \\
125 \text { bar } \\
(\mu \mathrm{m})\end{array}$ & $\begin{array}{c}\text { Time: } \\
\text { 16h, } \\
\text { load: } \\
150 \text { bar } \\
(\mu \mathrm{m})\end{array}$ & $\begin{array}{c}\text { Time: } \\
\text { 19h, } \\
\text { load: } \\
190 \text { bar } \\
(\mu \mathrm{m})\end{array}$ \\
\hline \multicolumn{11}{|c|}{ Spherical surface in the retainer guide } \\
\hline 1 & 0.32 & 0.46 & 1.22 & 1.62 & 1.89 & 1.52 & 1.74 & 1.03 & 0.78 & 0.95 \\
\hline 2 & 0.31 & 0.45 & 1.45 & 1.79 & 2.09 & 2.22 & 1.87 & 0.89 & 0.89 & 0.84 \\
\hline 3 & 0.35 & 0.51 & 1.56 & 1.53 & 2.29 & 2.00 & 1.66 & 0.88 & 0.87 & 1.00 \\
\hline 4 & 0.37 & 0.7 & 1.41 & 1.61 & 1.81 & 2.06 & 1.71 & 1.26 & 0.82 & 0.85 \\
\hline 5 & 0.32 & 0.55 & 1.53 & 1.55 & 1.82 & 1.89 & 2.10 & 0.92 & 0.78 & 0.87 \\
\hline Avr. & 0.33 & 0.53 & 1.43 & 1.62 & 1.98 & 1.94 & 1.82 & 1.00 & 0.83 & 0.90 \\
\hline $\begin{array}{l}\text { Std. } \\
\text { Dev. }\end{array}$ & 0.02 & 0.09 & 0.12 & 0.09 & 0.18 & 0.23 & 0.16 & 0.14 & 0.05 & 0.06 \\
\hline \multicolumn{11}{|c|}{ Spherical surface in the slipper-retainer } \\
\hline 1 & 11.28 & 11.74 & 10.35 & 11.56 & 13.61 & 7.16 & 4.71 & 3.23 & 3.39 & 6.46 \\
\hline 2 & 10.11 & 12.66 & 11.03 & 14.36 & 11.72 & 6.52 & 5.8 & 3.07 & 4.66 & 6.66 \\
\hline 3 & 12.84 & 15.36 & 10.85 & 12.64 & 12.18 & 6.87 & 4.55 & 3.31 & 5.15 & 7.14 \\
\hline 4 & 13.36 & 13.28 & 12.88 & 12.63 & 12.68 & 7.46 & 6.91 & 7.89 & 6.19 & 7.17 \\
\hline 5 & 12.06 & 14.27 & 15.19 & 14.05 & 13.33 & 7.16 & 6.62 & 5.34 & 7.15 & 8.13 \\
\hline Avr. & 11.93 & 13.46 & 12.06 & 13.05 & 12.70 & 7.03 & 5.72 & 4.57 & 5.31 & 7.11 \\
\hline $\begin{array}{l}\text { Std. } \\
\text { Dev. }\end{array}$ & 1.15 & 1.26 & 1.78 & 1.03 & 0.70 & 0.32 & 0.96 & 1.86 & 1.29 & 0.58 \\
\hline \multicolumn{11}{|c|}{ Conical surface of the $1^{\text {st }}$ piston } \\
\hline 1 & 0.39 & 2.88 & 3.73 & 4.27 & 3.25 & 2.01 & 2.28 & 2.35 & 2.29 & 2.04 \\
\hline 2 & 0.75 & 1.88 & 4.94 & 3.03 & 1.95 & 2.36 & 3.16 & 1.95 & 2.16 & 1.92 \\
\hline 3 & 0.4 & 1.75 & 3.88 & 3.23 & 2.5 & 2.01 & 2.1 & 2.26 & 2.25 & 2.12 \\
\hline 4 & 0.57 & 1.99 & 3.43 & 3.55 & 1.9 & 1.8 & 1.81 & 1.99 & 2.68 & 2.15 \\
\hline 5 & 0.6 & 2.43 & 3.23 & 4.26 & 2.28 & 2.67 & 2.6 & 2.3 & 2.78 & 1.69 \\
\hline Avr. & 0.54 & 2.19 & 3.84 & 3.67 & 2.38 & 2.17 & 2.39 & 2.17 & 2.43 & 1.98 \\
\hline $\begin{array}{l}\text { Std. } \\
\text { Dev. }\end{array}$ & 0.13 & 0.42 & 0.59 & 0.51 & 0.49 & 0.31 & 0.46 & 0.17 & 0.25 & 0.17 \\
\hline \multicolumn{11}{|c|}{ Conical surface of the $2^{\text {nd }}$ piston } \\
\hline 1 & 0.56 & 0.7 & 2.76 & 5.09 & 2.53 & 2.9 & 3.4 & 2.67 & 2.73 & 1.57 \\
\hline 2 & 0.65 & 0.36 & 3.36 & 3.15 & 1.91 & 2.78 & 2.08 & 2.61 & 2.62 & 1.41 \\
\hline 3 & 0.69 & 0.31 & 3.45 & 3.07 & 2.02 & 2.36 & 2.21 & 2.4 & 2.85 & 1.99 \\
\hline 4 & 0.45 & 0.88 & 3.9 & 2.27 & 2.32 & 2.44 & 2.12 & 2.51 & 2.67 & 1.81 \\
\hline 5 & 0.47 & 0.77 & 3.32 & 2.19 & 2.53 & 2.87 & 3.23 & 2.19 & 2.7 & 1.61 \\
\hline Avr. & 0.56 & 0.60 & 3.36 & 3.15 & 2.26 & 2.67 & 2.61 & 2.48 & 2.71 & 1.68 \\
\hline $\begin{array}{l}\text { Std. } \\
\text { Dev. }\end{array}$ & 0.09 & 0.23 & 0.36 & 1.05 & 0.26 & 0.23 & 0.58 & 0.17 & 0.08 & 0.20 \\
\hline
\end{tabular}


Values compared in table 5 are shown in a form of a columnar chart in the figure. 8.

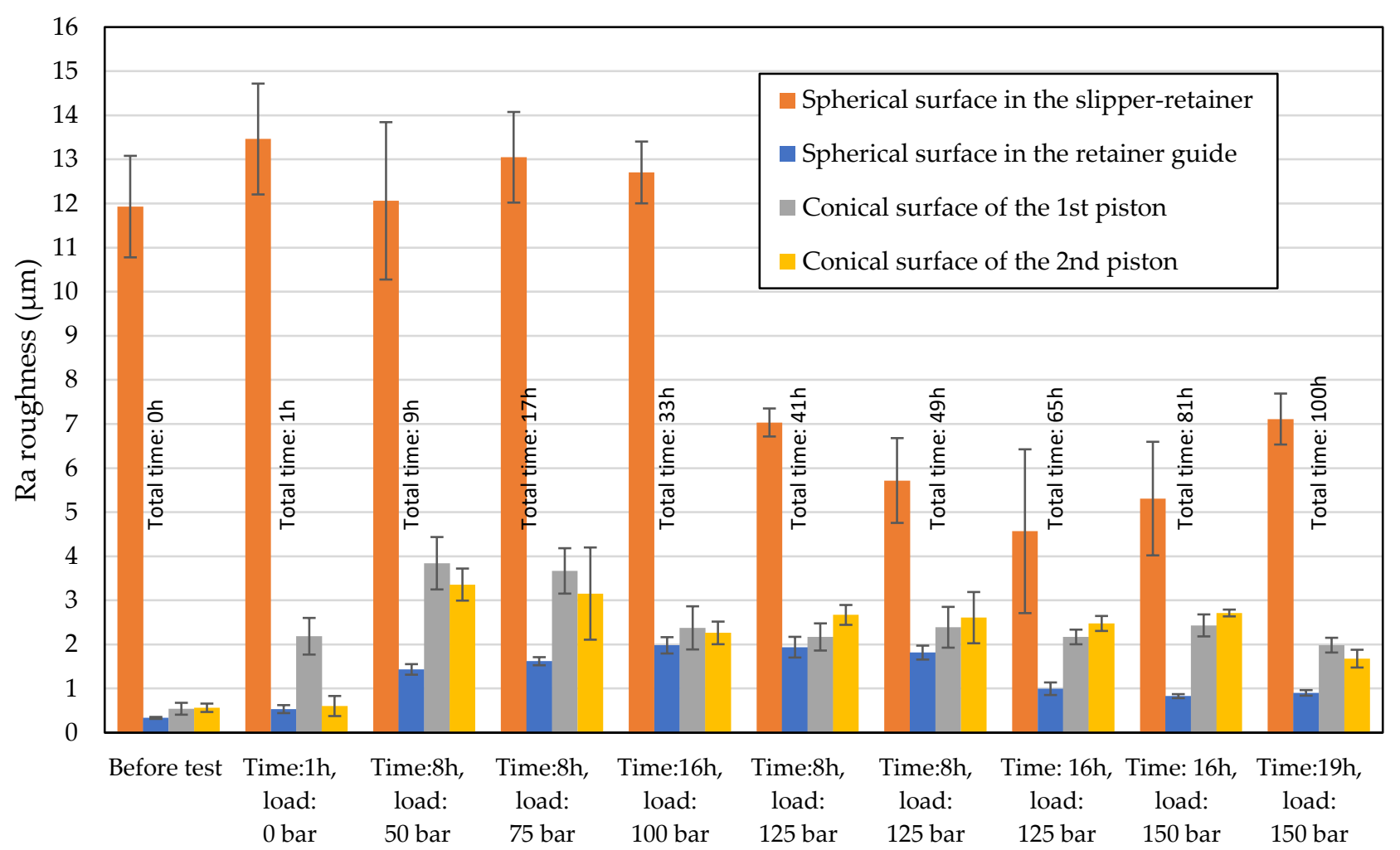

Figure 8. Roughness measurement results of all tested parts

Based on the obtained results is the visible high surface roughness of the spherical surface in the slipper-retainer, which is typical for parts manufactured during the SLM process, additionally subjected to sandblasting [33]. The significant surface roughness reduction $(66 \%)$ if visible after exceeding the pump pressure value equal to $125 \mathrm{bar}$ and kept by 32 hours of exploitation. Further load increasing caused a slight increase of the Ra parameter in this part. In the case of the original parts (conical surface of the retainer guide and two pistons) there is visible an increase in the surface roughness which is equal to $500 \%$ in the case of the retainer guide, and $555 \%$ in the case of the pump pistons. It was caused by collaboration with the AM element. The unevenness scratched the surfaces of the other elements of the pump. After exceeding the mentioned total values the surface roughness of three tested original pump parts started to decrease and reached the following values in comparison to the initial stage: retainer guide - $172 \%$, and pump pistons $267 \%$. Such phenomenon is strictly related to different materials used for the production of the retainer guide (hardened steel) and pump pistons (tin bronze C90700). The significant wear took place in the case of pump pistons, which had been subjected to deeper microscope investigation based on geometrical analysis. The images from each stage are shown in table 6. 
Table 6. The surface condition of two tested cylindrical surfaces of the pump pistons

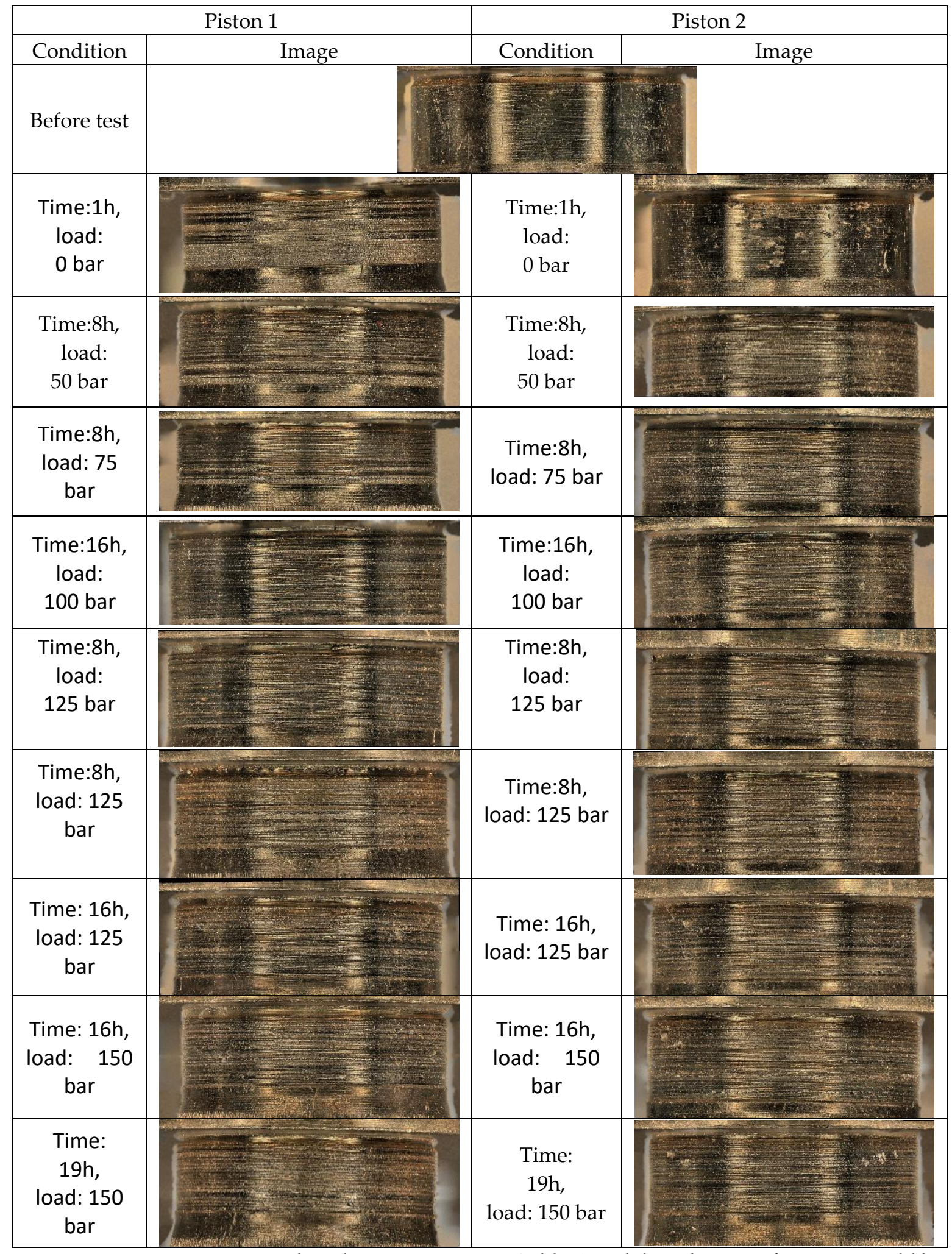

Based on the register images (table 6) and data shown in figure 8 it could be observed different wear of two analyzed pistons after 1-hour test without load. The most significant unevenness in the surface roughness of the conical pistons is visible at the first part of the test campaign, which has been better visualized in figure 9 . 


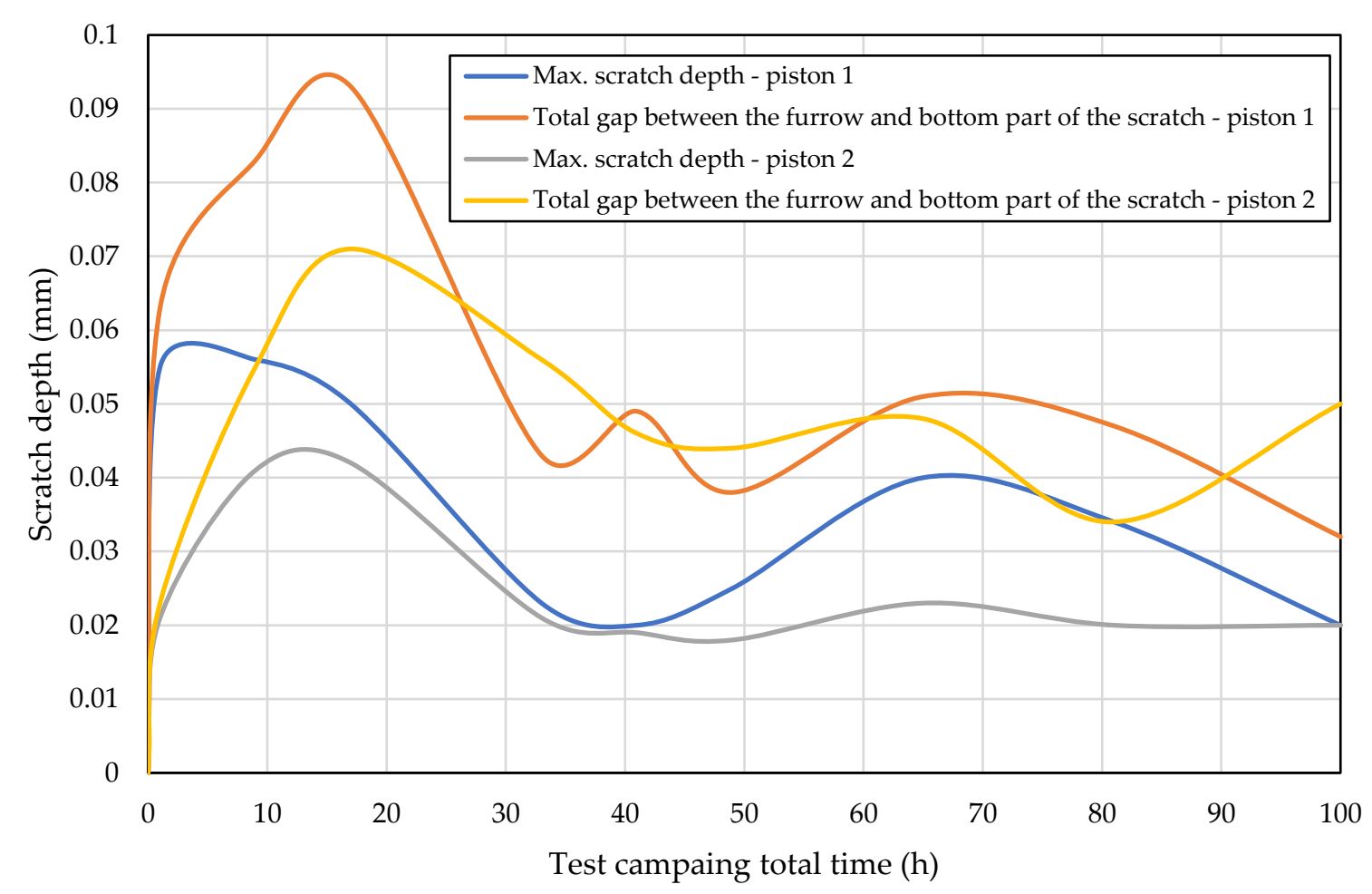

Figure 9. Geometrical measurement results of two selected pump pistons

It could be observed that scratches depth in two pistons increased after the first 16 hours, where the load value did not exceed 100 bars. After increasing the pump pressure to 100 bars, the total scratches depth decreased to a value of $64 \%$ in the case of the first piston and $52 \%$ in the case of the second piston. A similar situation took place with the total gap between the furrow and the bottom part of the scratches in two analyzed pistons. After 40 hours of the pump exploitation, the values of those two factors were stabilized and had a value between $0.02-0.05 \mathrm{~mm}$.

In the case of the retainer guide, there were no such significant changes after the whole test campaign. There were some irregular scratches but not in the whole area of the conical surface of the retainer guide. After the last test stage (with the total load equal to 150 bars), there was a large defect in the conical surface occurred (figure 10).
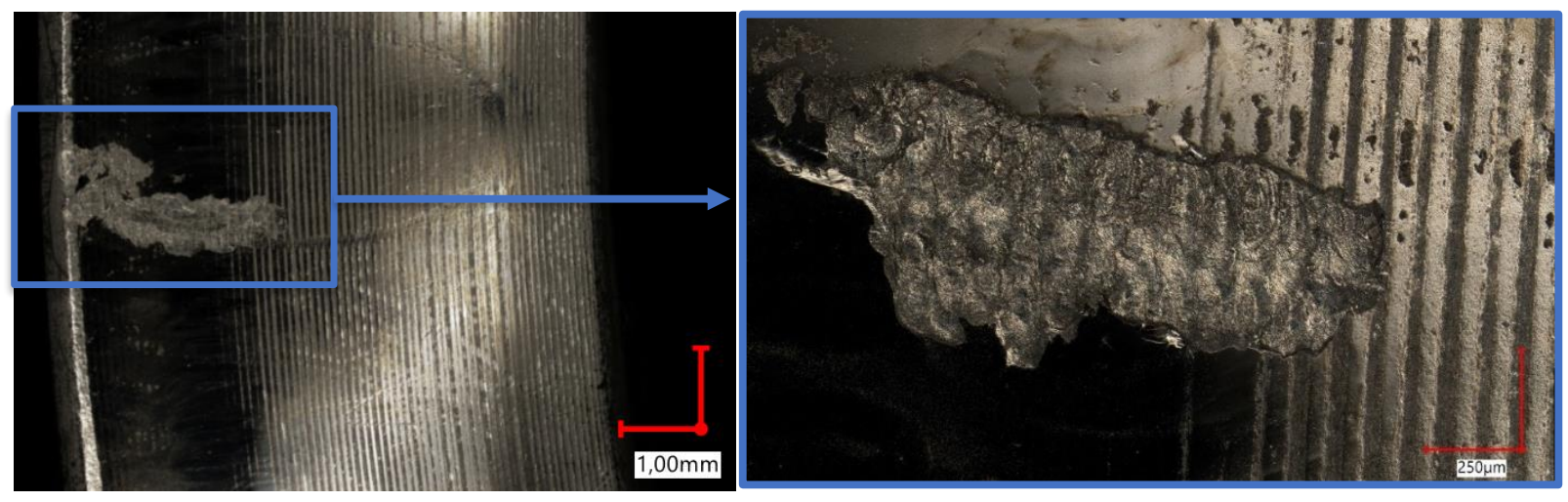

Figure 10. The hollow defect appeared after the last test stage 
Taking into account the defect shape shown in figure 10 it could be concluded that such defect has a fatigued character. Such phenomenon is similar to Rolling Contact Fatigue (RCF) spalling effect, because of characteristic defect shape with visible scaly structure [35]. Due to the high roughness of the surface of the printed element, the lubricating film was broken and the cooperating surfaces were in direct contact. This effect was conducive to the cyclical increase in stresses and the material particles being pulled out. As a result, spalling craters were formed on the surface of the elements (Fig. 10).

As it was mentioned, after each stage of the test the pump characteristics were measured. Results are presented in Figure 11. The dotted lines represent the new pump characteristics, continuous lines represent the curves for the pump with replaced slipper-retainer.

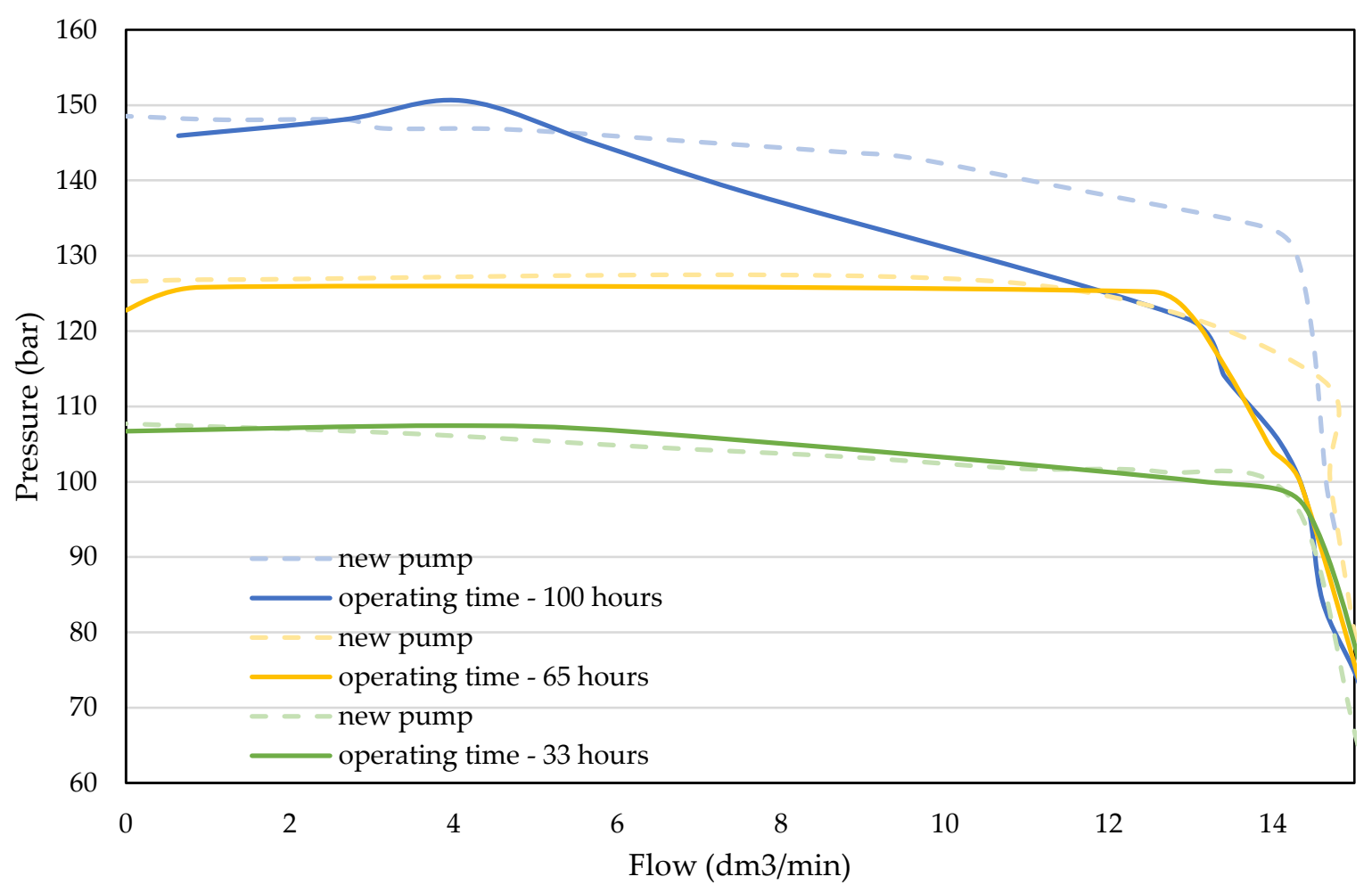

Figure 11. The pump characteristics

The measured curves for 100 and 125 bar are consistent with the new pump ones. The differences in runs are neglected and can be a result of system dynamic behaviors. A significant difference is observed with the curve for 150 bar - with the growing flow, the system pressure decrease. That phenomenon may be caused by serious defects in tested parts. 


\section{Conclusions}

Based on the conducted research the following conclusion could be stated:

The postprocessing of the AM parts based only on the sandblasting process is not sufficient to properly reduce their surface roughness, the further grinding of the cooperating surface could significantly reduce the wear.

Surface roughness of additive manufactured retainer- slipper has been decreased after exploitation in 125 bar of the pump load. Persisting the load on the level of 125 bars for 32 hours allowed to reduce the surface roughness in a value of $67 \%$.

After exceeding the load value above 125 bars (which is $45 \%$ of the nominal pressure), the surface roughness of the slipper-retainer spherical surface started to increase.

Exceeding the total load value equal to 150 bars caused significant wear of the retainer guide, which has a spalling-like character.

After 32 hours of pump operation time with 125 bar pressure (total operating time 65 hours), the pump operating parameters were consistent with theoretical ones. Raise of the system pressure (to 150 bars) resulted in significant wear. With the growing wear of the elements of the pump, the operation parameters deteriorated.

Additive manufactured spare parts obtained with the use of PBF technologies dedicated to metallic powders allow to continue exploitation of such devices as hydraulic pumps until the arrival of the original parts.

Due to the significant wear of the elements, this solution is not recommended for fragile and precise systems. The debris in oil may have caused damages to the other parts. In order to avoid that problem, an additional filter in the system is recommended.

Author Contributions: Conceptualization, A.K.,. and J.K.; methodology, A.B., A.K., J.K., and J.Ł.; software, A.K; validation, J.Ł., A.B., K.G. and J.K.; formal analysis, A.K., and. J.Ł; investigation, A.K., J.Ł., A.B., and J.K.; resources, A.B., and K.G.; data curation, A.K., J.K., and M.M.; writing-original draft preparation, A.K., and J.K.; writing - review and editing, M.M.; visualization, J.Ł., and A.K; supervision, A.B., and K.G.; project administration, A.K., and J.K; funding acquisition, J.K., and K.G. All authors have read and agreed to the published version of the manuscript

Funding: Please add: This research was funded by the university research grant No. 22-889

Data Availability Statement: "Not applicable"

Conflicts of Interest: The authors declare no conflict of interest. 


\section{References}

1. C.S. Frandsen, M.M. Nielsen, A. Chaudhuri, J. Jayaram, K. Govindan, In search for classification and selection of spare parts suitable for additive manufacturing: a literature review, International Journal of Production Research. 58 (2020) 970 996. https://doi.org/10.1080/00207543.2019.1605226.

2. P. Rokicki, B. Kozik, G. Budzik, T. Dziubek, J. Bernaczek, L. Przeszlowski, O. Markowska, B. Sobolewski, A. Rzucidlo, Manufacturing of aircraft engine transmission gear with SLS (DMLS) method, Aircraft Engineering and Aerospace Technology. 88 (2016) 397-403. https://doi.org/10.1108/aeat-05-2015-0137.

3. N. Hopkinson, P. Dickens, Rapid prototyping for direct manufacture, Rapid Prototyping Journal. 7 (2001) $197-202$. https://doi.org/10.1108/EUM0000000005753.

4. E. Chlebus, Technologies in rapid product development, Bulletin of the Polish Academy of Sciences: Technical Sciences. 55 (2007) 71-83.

5. A. Kochan, Rapid prototyping trends, Rapid Prototyping Journal. $3 \quad$ (1997) 150-152. https://doi.org/10.1108/13552549710191863.

6. P. Platek, K. Damaziak, J. Malachowski, P. Kupidura, R. Wozniak, M. Zahor, Numerical study of modular 5.56 mm standard assault rifle referring to dynamic characteristics, Defence Science Journal. 65 (2015) 431-437. https://doi.org/10.14429/dsj.65.8259.

7. J. Malachowski, K. Damaziak, P. Platek, M. Sarzynski, P. Kupidura, R. Wozniak, M. Zahor, Numerical and experimental failure analysis of rifle extractor, Engineering Failure Analysis. 62 (2016) 112-127. https://doi.org/10.1016/j.engfailanal.2016.01.004.

8. B. Borsuk-Nastaj, M. Młynarski, Zastosowanie technologii selektywnego topienia laserem (SLM) w wykonawstwie stałych uzupełnień protetycznych, Protetyka Stomatologiczna. 62 (2012) 203-210.

9. M. Ruffo, C. Tuck, R. Hague, Make or buy analysis for rapid manufacturing, Rapid Prototyping Journal. 13 (2007) $23-29$. https://doi.org/10.1108/13552540710719181.

10. P. Bajaj, A. Hariharan, A. Kini, P. Kürnsteiner, D. Raabe, E.A. Jägle, Steels in additive manufacturing: A review of their microstructure and properties, Materials Science and Engineering A. 772 (2020). https://doi.org/10.1016/j.msea.2019.138633.

11. J. Kluczyński, L. Śnieżek, K. Grzelak, J. Janiszewski, P. Płatek, J. Torzewski, I. Szachogłuchowicz, K. Gocman, Influence of Selective Laser Melting Technological Parameters on the Mechanical Properties of Additively Manufactured Elements Using 316L Austenitic Steel, Materials. 13 (2020) 1449. https://doi.org/10.3390/ma13061449.

12. J. Kluczyński, L. Śniezek, K. Grzelak, J. Torzewski, I. Szachogłuchowicz, M. Wachowski, J. Łuszczek, Crack growth behavior of additively manufactured 316L steel-influence of build orientation and heat treatment, Materials. 13 (2020). https://doi.org/10.3390/MA13153259.

13. J. Kluczyński, L. Śnieżek, K. Grzelak, A. Oziębło, K. Perkowski, Hot isostatic pressing influence on the mechanical properties of selectively laser-melted 316L steel, 68 (2020) 1413-1424. https://doi.org/10.24425/bpasts.2020.135396.

14. . Śniezek, K. Grzelak, J. Torzewski, J. Kluczyński, Study of the mechanical properties components made by SLM additive technology, in: 11th International Conference on Intelligent Technologies in Logistics and Mechatronics Systems, ITELMS 2016, 2016: pp. 145-153.

15. J. Sienkiewicz, P. Płatek, F. Jiang, X. Sun, A. Rusinek, Investigations on the Mechanical Response of Gradient Lattice Structures Manufactured via SLM, Metals. 10 (2020) 213. https://doi.org/10.3390/met10020213.

16. P. Płatek, K. Rajkowski, K. Cieplak, M. Sarzyński, J. Małachowski, R. Woźniak, J. Janiszewski, Deformation process of 3D printed structures made from flexible material with different values of relative density, Polymers. 12 (2020). https://doi.org/10.3390/POLYM12092120.

17. J. Suryawanshi, K.G. Prashanth, U. Ramamurty, Mechanical behavior of selective laser melted 316L stainless steel, Materials Science and Engineering A. 696 (2017) 113-121. https://doi.org/10.1016/j.msea.2017.04.058.

18. J.B. Jones, D.I. Wimpenny, G.J. Gibbons, Additive manufacturing under pressure, Rapid Prototyping Journal. 21 (2015) 8997. https://doi.org/10.1108/RPJ-02-2013-0016.

19. V. Verboeket, H. Krikke, Additive Manufacturing: A Game Changer in Supply Chain Design, Logistics. 3 (2019) 13. https://doi.org/10.3390/logistics3020013.

20. V. Verboeket, H. Krikke, Additive Manufacturing: A Game Changer in Supply Chain Design, Logistics. 3 (2019) 13. https://doi.org/10.3390/logistics3020013.

21. L. Rickenbacher, A. Spierings, K. Wegener, An integrated cost-model for selective laser melting (SLM), Rapid Prototyping Journal. 19 (2013) 208-214. https://doi.org/10.1108/13552541311312201.

22. M. Burkhart, J.C. Aurich, Framework to predict the environmental impact of additive manufacturing in the life cycle of a commercial vehicle, Procedia CIRP. 29 (2015) 408-413. https://doi.org/10.1016/j.procir.2015.02.194.

23. D.B. Short, A. Sirinterlikci, P. Badger, B. Artieri, Environmental, health, and safety issues in rapid prototyping, Rapid Prototyping Journal. 21 (2015). https://doi.org/10.1108/RPJ-11-2012-0111.

24. H. Paris, H. Mokhtarian, E. Coatanéa, M. Museau, I.F. Ituarte, Comparative environmental impacts of additive and subtractive manufacturing technologies, CIRP Annals - Manufacturing Technology. $65 \quad$ (2016) $29-32$. https://doi.org/10.1016/j.cirp.2016.04.036. 
25. R. Lifset, 3D Printing and Industrial Ecology, Journal of Industrial Ecology. 21 (2017) S6-S8. https://doi.org/10.1111/jiec.12669.

26. S. Yang, T. Page, Y. Zhang, Y.F. Zhao, Towards an automated decision support system for the identification of additive manufacturing part candidates, Journal of Intelligent Manufacturing. 31 (2020) 1917-1933. https://doi.org/10.1007/s10845020-01545-6.

27. B. Hapuwatte, K.D. Seevers, F. Badurdeen, I.S. Jawahir, Total Life Cycle Sustainability Analysis of Additively Manufactured Products, Procedia CIRP. 48 (2016) 376-381. https://doi.org/10.1016/j.procir.2016.03.016.

28. B. Hapuwatte, K.D. Seevers, F. Badurdeen, I.S. Jawahir, Total Life Cycle Sustainability Analysis of Additively Manufactured Products, Procedia CIRP. 48 (2016) 376-381. https://doi.org/10.1016/j.procir.2016.03.016.

29. Y. Zhu, Y. Yang, Y. Wang, T. Peng, L. Zhang, H. Yang, Localized Property Design and Gradient Processing of a Hydraulic Valve Body using Selective Laser Melting, IEEE/ASME Transactions on Mechatronics. 4435 (2020) 1-1. https://doi.org/10.1109/tmech.2020.3019303.

30. T. Peng, Y. Wang, Y. Zhu, Y. Yang, Y. Yang, R. Tang, Life cycle assessment of selective-laser-melting-produced hydraulic valve body with integrated design and manufacturing optimization: A cradle-to-gate study, Additive Manufacturing. 36 (2020) 101530. https://doi.org/10.1016/j.addma.2020.101530.

31. Y. Zhu, Y. Yang, P. Lu, X. Ge, H. Yang, Influence of surface pores on selective laser melted parts under lubricated contacts: a case study of a hydraulic spool valve, Virtual and Physical Prototyping. 14 (2019) 395-408. https://doi.org/10.1080/17452759.2019.1633930.

32. J. Zou, Y. Zhu, M. Pan, T. Xie, X. Chen, H. Yang, A study on cavitation erosion behavior of AlSi10Mg fabricated by selective laser melting (SLM), Wear. 376-377 (2017) 496-506. https://doi.org/10.1016/j.wear.2016.11.031.

33. J. Kluczyński, L. Sniezek, K. Grzelak, J. Torzewski, The influence of layer re-melting on tensile and fatigue strength of selective laser melted 316L steel, in: 12th International Conference on Intelligent Technologies in Logistics and Mechatronics Systems, ITELMS 2018, 2018: pp. 115-123.

34. J. Kluczyński, L. Śnieżek, K. Grzelak, J. Torzewski, I. Szachogłuchowicz, A. Oziębło, K. Perkowski, M. Wachowski, M. Małek, The influence of heat treatment on low cycle fatigue properties of selectively laser melted 3161 steel, Materials. 13 (2020) 1-20. https://doi.org/10.3390/ma13245737.

35. K. Grzelak, J. Kluczyński, I. Szachogłuchowicz, J. Łuszczek, L. Śnieżek, J. Torzewski, Modification of structural properties using process parameters and surface treatment of monolithic and thin-walled parts obtained by selective laser melting, Materials. 13 (2020) 1-12. https://doi.org/10.3390/ma13245662.

36. Y. Wang, T. Peng, Y. Zhu, Y. Yang, R. Tang, A comparative life cycle assessment of a selective-laser-melting-produced hydraulic valve body using design for Property, Procedia CIRP. $90 \quad(2020) \quad 220-225$. https://doi.org/10.1016/j.procir.2020.01.095.

37. L. Surówka, Stationary research of working machine hydraulic systems, Studies\&Proceedings of Polish Association for Knowledge Management. 48 (2011) 60-72.

38. Y. Zhu, G. Li, R. Wang, S. Tang, H. Su, K. Cao, Intelligent fault diagnosis of hydraulic piston pump based on wavelet analysis and improved alexnet, Sensors (Switzerland). 21 (2021) 1-18. https://doi.org/10.3390/s21020549.

39. H. Tang, Z. Fu, Y. Huang, A fault diagnosis method for loose slipper failure of piston pump in construction machinery under changing load, Applied Acoustics. 172 (2021). https://doi.org/10.1016/j.apacoust.2020.107634.

40. S. Tang, S. Yuan, Y. Zhu, G. Li, An integrated deep learning method towards fault diagnosis of hydraulic axial piston pump, Sensors (Switzerland). 20 (2020) 1-20. https://doi.org/10.3390/s20226576.

41. Danfoss Power Solutions, Repair Instructions Failure Analysis and Parts Evaluation, 2014.

42. Eaton Corporation, Pump Failure Analysis, 2002.

43. J.C. Hildreth, D. Chen, Assessment of Heavy Equipment Operating Cost Estimates from Annual Data, International Journal of Construction Engineering and Management. 7 (2018) 125-132. https://doi.org/10.5923/j.ijcem.20180704.01.

44. Caterpillar, Caterpillar Performance Handbook, January 2014, SEBD0351-44, 2014. www.hawthornecat.com. 